\title{
The Influence of High-tech Qualification Accreditation on Enterprise Innovation Performance Based on an Empirical Study Using PSM
}

\author{
SUN Yibo ${ }^{1, a}$, SUN Jiazheng ${ }^{2, b}$ \\ ${ }^{1}$ School of Economics and Management Beijing Information Science \& Technology University Beijing, China \\ ${ }^{2}$ School of Economics and Management Beijing Information Science \& Technology University Beijing, China
}

\begin{abstract}
In order to promote China's economy high-quality development, the country has continuously lowered the certification standards for high-tech enterprises. The existing research literature has not yet reached a clear conclusion about the impact of high-tech qualification certification on enterprise innovation performance. This paper uses the Shanghai and Shenzhen A-share listed companies from 2013 to 2018 as a research sample. Through the propensity score matching method, it is found that the implementation of the high-tech enterprise identification policy has an effect on the innovation performance of the enterprise, especially for strategic innovation represented by the number of non-invention patent applications. The subsample results show that the identification policy has a more obvious impact on the innovation performance of non-state-owned enterprises, young enterprises and larger enterprises. Finally, based on the results of the research, it is proposed to continuously improve the identification policy, guide enterprises to make substantial innovations, and implement hierarchical tax rates for different types of enterprises to help improve the identification policies for high-tech enterprises.
\end{abstract}

\section{INTRODUCTION}

As China's economy turns to the stage of high-quality development, innovation has become the source of highquality development of China's economy. High-tech enterprises, as the main force to enhance China's independent innovation ability, play a decisive role in the process of improving the quality of China's economic growth. However, due to the high risk, high investment, externality and other characteristics of innovation activities, many enterprises in China lack the willingness to innovate. Therefore, it is necessary for the government to intervene the innovation activities of enterprises. Since the 1990s, China has introduced the policy of identifying high-tech enterprises for the first time, supplemented by relevant fiscal and tax policies. Nevertheless, due to the lack of uniform measurable standards, the effect of the policy implementation is unsatisfactory. In 2008, the Ministry of Science and Technology, the Ministry of Finance and the State Administration of Taxation jointly promulgated the "Administrative measures for the determination of high and new technology enterprises", which unified the certification standards nationwide. Since then, the identification of high-tech enterprises in China has entered the stage of standardization. In 2016, in order to increase the support for high-tech enterprises, especially small and medium-sized enterprises, encourage

a757342397@qq.com

b1622693798@qq.com more enterprises to increase investment in innovation, and improve the innovation ability of the whole society, the Ministry of Science and Technology and other departments revised their methods and lowered several standards such as scientific and technological personnel and R\&D expenses.

In this context, China has set off a rush to identify high-tech enterprises. However, the occurrence of "innovation for identification", "pseudo high-tech" and various "fraud subsidy" have made the implementation effect of the high-tech enterprise identification policy (hereinafter referred to as the identification policy) highly controversial. From the perspective of enterprise innovation performance, the impact of high-tech enterprise identification policy on enterprise innovation performance mainly has the following two views. One view is that the tax reduction and exemption enjoyed by the enterprise after the certification may "crowd out" the company's R\&D investment; another view is that the tax incentives and government subsidies obtained by enterprises after the qualification of high-tech enterprises can reduce the $R \& D$ cost and promote the innovation performance of enterprises. By the end of 2018, the number of nationally recognized high-tech enterprises has exceeded 180,000, and the state has implemented tax reductions and exemptions for high-tech enterprises of about 50 billion yuan. Then, what impact does the implementation of the identification policy affect the 
innovation performance of enterprises? Since the implementation of the recognition policy in 2016, many companies have been recognized as high-tech enterprises for three years, and the implementation effect of the policy has shown. Therefore, this paper will take the identification policy issued in 2016 as the research object, and test the impact of its implementation on enterprise innovation performance through empirical analysis, so as to provide reference for the implementation of subsequent policies and effect evaluation.

\section{LITERATURE REVIEW AND RESEARCH HYPOTHESIS}

As one of the policies implemented by the government to encourage enterprises to carry out innovation activities and enhance national independent innovation ability, the identification policy has an important impact on the construction of an innovative country in China. After obtaining the qualification of high-tech enterprises, enterprises can enjoy preferential policies such as tax reduction and fiscal subsidies. Research on the impact of identification policies on corporate innovation performance is different from direct research on the impact of tax relief or fiscal subsidies on corporate innovation performance. Although the standards of the identification policy have been continuously lowered in recent years, the tax rate enjoyed by enterprises has basically remained unchanged. At the same time, identification policy will enhance the corporate reputation and bring greater impact to the enterprise.

Through combing existing literature, it is found that the research on the effect of tax relief or financial subsidies on the innovation performance of enterprises is richer[1][2][3], but there are few literatures on the innovation performance of enterprises after the implementation of the identification policy. Moreover, most studies take the identification policy issued in 2008 as the research object, and no consensus is reached on the impact effect. On the one hand, some scholars believe that the identification policy has a positive impact on the innovation performance of enterprises. For example, Chen Zhen-zhen et al.[4] believe that high-tech enterprise identification can significantly encourage enterprises to increase R\&D investment; Xu Ling-ling and Liu Fang[5] through research found that high-tech enterprise identification can significantly stimulate enterprise innovation, and the effect is more significant in areas with low financial development; Sun Gang[6] found that the identification policy can significantly increase the number of enterprise invention patent applications and the number of formal invention patent applications obtained within four years. On the other hand, some scholars believe that the identification policy has no significant impact on enterprise innovation investment and performance; $\mathrm{Xu}$ Changsheng et al.[7] used the breakpoint regression method to empirically found that the identification policy does not significantly promote the innovation activities of enterprises; Liu Li[8] took enterprises on the New Third Board in Hubei Province from 2015 to 2017 as the research object, and used the propensity score matching method to empirically find that the identification policy have no significant incentive effect on enterprises' innovation input. Tan Long et al.[9] found that most of the enterprises that passed the identification did not increase the number of patent applications after identification.

In addition to enjoying tax preferences and financial subsidies, enterprises can also apply for various special funds and scientific and technological projects. It is also easier to obtain national, provincial and municipal scientific research funds and financial allocation support. In addition, the recognized high-tech enterprises can also enjoy the local government's fund prize of 100,000 yuan to 2 million yuan. For example, Shandong Province is the first recognized high-tech enterprise to receive a one-time subsidy of 100,000 yuan, which reduces the R\&D cost of enterprises to a certain extent. Moreover, after obtaining the recognition certificate, the enterprise greatly improves its brand image, makes it easier to obtain venture capital and loans from major Banks, and obtains funds from financing markets such as the Growth Enterprise Board and the Science innovation Board. Based on this, the hypothesis $H_{1}$ is proposed: the identification policy has a positive impact on the enterprise innovation performance, that is, the identification policy can improve the enterprise innovation performance.

Besides, it is found that the incentive effect of the identification policy is related to the property rights of the enterprise, the life cycle in which it is in, and the total asset scale of the enterprise. Lei Gen-qiang et al.[10] found that the identification policy has a significant impact on the substantial innovation of enterprises. Compared with private enterprises, the identification policy has a stronger additional incentive effect on stateowned enterprises. Xie Hai-yang[11] et al. used the DIDPSM method to empirically found that it can significantly improve the R\&D performance of state-owned enterprises. Zhou Wei[12] analyzed the high-tech enterprises in Hunan Province through empirical analysis and found that the identification policy has a significant role in promoting non-state-owned enterprises. Xu Ling-ling[13] used A-shares as a sample of empirical research and found that the identification policy can significantly stimulate technological innovation in non-state-owned enterprises, and political connections can significantly positively regulate this incentive effect. Moreover, the different scale of companies have different sensitivity to the identification policy. It had a more obvious incentive effect on the innovation performance of large enterprises. Zeng Jing-jing et al.[14] used the Differences-inDifferences method to study and found that compared with small and medium-sized enterprises, large enterprises were more sensitive to the identification policy. At the same time, considering that enterprises are in different life cycle stages, the incentive effect of policies will be different. Zhang $\mathrm{Yu}[15]$ constructed a multiple regression model with high-tech enterprises as samples, and found that the recognition policy had a higher incentive effect on the innovation of mature enterprises. Based on the above analysis, a hypothesis is proposed:

$\mathrm{H}_{2}$ : The identification policy has different effects on the innovation performance of different types of 
enterprises: compared with state-owned enterprises, the identification policy has a more obvious incentive effect on the innovation of non-state-owned enterprises; compared with young enterprises, the identification policy has a greater incentive effect on mature enterprises; the larger the enterprise, the more sensitive it is to the identification policy.

\section{ReseARCh DESIGN}

\subsection{Sample screening and data sources}

In this paper, Shanghai and Shenzhen A-share listed companies are selected as the research objects, and the sample time is from 2013 to 2018. The enterprises that passed the high-tech enterprise identification for the first time in 2016 are selected as the experimental group, and non-high-tech enterprises are selected as the control group. The following samples were eliminated: (1) samples with missing variables; (2)the identified objects are the listed company's subsidiaries, company projects, company technology center and other samples; (3) samples of special treatment and delisting. Finally, 6 periods of balanced panel data were obtained, with a total of 736 research samples and 4,416 observation data. Enterprise qualification identification data comes from the China Stock Market \& Accounting Research Database. Total assets, debt to asset ratio, corporate attributes, return on total assets, return on equity, net profit margin on sales, company establishment date, current ratio data come from wind database. The data of patent applications, patent applications for invention and non-invention patent applications are from soopat website. In order to avoid the influence of outliers, $1 \%$ and $99 \%$ bits of continuous variables were reduced.

\subsubsection{Variable definitions}

- Result variable. Considering the number of patents granted has a long review period and a delayed effect and will be influenced by other factors such as the annual fee. As a result, this paper use for reference of the research of Ye Ming-que et al.[16] and Li Wenjing et al.[17]. The logarithmic value of the number plus one is used to measure the innovation performance of the company. The logarithm of the number of invention patent applications of the company plus one in the year is used as the measurement index of the company's substantive innovation performance, and the logarithm of the number of patent applications of the company plus one in the year is used as the performance of enterprise strategic innovation.

- $\quad$ Treatment variable. Referring to Lei Gen-qiang et al.[10], the identification of high-tech enterprises is set as the dummy variable as the treatment variable. A high-tech enterprise that has been recognized has a three-year validity period, that is, the year when the company first passed the certification in 2016 and the two years within the validity period are recorded as 1 , and the enterprise that has not obtained the high-tech enterprise qualification certification from 2013 to 2018 is recorded as 0 .

- Match variables. Referring to existing research, this paper selects enterprise scale, debt to asset ratio, return on total assets, net profit margin on sales, enterprise age, and current ratio as control variables. The definition and calculation method of each variable are shown in Table 1.

TABLE I. VARIABLE NAME AND DEFINITION

\begin{tabular}{|c|c|c|c|}
\hline $\begin{array}{l}\text { Variable } \\
\text { Type }\end{array}$ & Variable Name & $\begin{array}{l}\text { Variable } \\
\text { Symbol }\end{array}$ & Variable Define \\
\hline \multirow{3}{*}{ result variable } & number of patent applications & total & $\begin{array}{c}\text { the logarithm of the number of patent applications is taken after adding } \\
\text { one }\end{array}$ \\
\hline & $\begin{array}{l}\text { number of invention patent } \\
\text { applications }\end{array}$ & invent & $\begin{array}{c}\text { the logarithm of the number of invention patent applications is taken } \\
\text { after adding one }\end{array}$ \\
\hline & $\begin{array}{l}\text { number of invention non-patent } \\
\text { applications } \\
\end{array}$ & other & $\begin{array}{l}\text { the logarithm of the number of non-patent applications is taken after } \\
\text { adding one }\end{array}$ \\
\hline $\begin{array}{l}\text { treatment } \\
\text { variable }\end{array}$ & $\begin{array}{l}\text { recognition of high-tech } \\
\text { enterprises }\end{array}$ & policy & $\begin{array}{l}\text { according to "the Management Measures for The Recognition of High- } \\
\text { tech Enterprises" in 2016, the value of the enterprise approved for the } \\
\text { first time in } 2016 \text { is } 1 \text {, otherwise it is } 0\end{array}$ \\
\hline \multirow{8}{*}{$\begin{array}{l}\text { matching } \\
\text { variable }\end{array}$} & enterprise scale & size & the $\log$ of total assets at the end of the period \\
\hline & lev & lev & the ratio of total assets to total liabilities at the end of the period \\
\hline & roa & roa & the ratio of net profit to net assets at the end of the period \\
\hline & npm & npm & the ratio of net profit to sales revenue \\
\hline & enterprise age & old & year minus year of incorporation plus one \\
\hline & $\mathrm{cr}$ & $\mathrm{cr}$ & ratio of current assets to current liabilities \\
\hline & property right character & soe & state-owned enterprises take 1 and other enterprises take 0 \\
\hline & annual effect & year & take 0 before 2016 and 1 after 2016 \\
\hline
\end{tabular}

\subsection{Model design}

When evaluating the implementation effect of the recognition policy, there will be two kinds of problems. One is that we cannot observe the innovation performance of the enterprises that have obtained high-tech enterprise qualification recognition without obtaining the high-tech enterprise qualification recognition, that is, the "counterfactual state". The second is the endogenous problem caused by selective bias. Since the enterprise is not considered as a high-tech enterprise randomly, we 
cannot judge whether the improvement of the enterprise's innovation performance is affected by the policy identification or the enterprise's own reasons. One of the solutions to above two kinds of problems is the propensity score matching method.

The basic principle of this method is: in order to reduce the selection bias, when evaluating the implementation effect of the identification policy, we need to find the sample as the observation value of the experimental group (high-tech enterprise) in the control group (non-high-tech enterprise). Except for the variable of whether to obtain the qualification of high-tech enterprises, the overall characteristics of the two are as similar as possible. Generally speaking, choosing only one variable (such as enterprise size) as the matching variable often fails to achieve satisfactory matching results. Therefore, it is necessary to use the PSM method to integrate multiple matching variables into one indicator (that is, the propensity score value). By matching individuals with similar propensity scores, the difference between the two individuals is estimated, that is, the effect of the enterprise on the innovation performance after the enterprise is recognized as a high-tech enterprise. The specific process is as follows:

First, divide the sample into two groups: the experimental group (the companies that passed the certification for the first time in 2016, policy $_{i t}=0$ ) and the control group (the non-high-tech companies, policy $_{i t}=1$ ).

Secondly, set up the Logit model with enterprise scale, debt to asset ratio, return on total assets, net profit margin on sales, enterprise age, and current ratio as match variables.

$$
P_{i t}\left(X_{i t}\right)=\operatorname{Pr}\left(\text { policy }_{i t}=1 \mid X_{i t}\right)=\exp \left(\beta X_{i t}\right) /\left[1+\exp \left(\beta X_{i t}\right)\right]
$$

Where $\exp (\cdot) /[1+\exp (\cdot)]$ represents the distribution function of logistic regression, $X_{i t}$ represents a series of matching variables of firm $i$ in year $t$, and $\beta$ is the corresponding parameter vector.

Again, after estimating the parameter estimation value $\beta$, calculate the propensity score of each company $\left(P S_{i t}\right)$ after obtain the qualification.

$$
P S_{i t}=P_{i t}\left(X_{i t}\right)
$$

Finally, the experimental group was matched with the control group according to the calculated propensity score. Since it is very difficult to find two samples with exactly the same propensity matching value, the nearest neighbor matching method, radius matching method and kernel matching method are often used to match the two groups of samples. In this paper, the "nuclear matching" method is used to match the enterprises in the experimental group and the control group. Matched companies are used as the observed values under the "counterfactual state" of the experimental group companies. The average processing effect (ATT) is estimated by comparing the innovation performance differences between the experimental group and the matched control group. If the ATT symbol is positive, it indicates that the innovation performance of enterprises will be improved after its obtain the qualification of high-tech enterprise. On the contrary, it indicates that the enterprises without qualification recognition of high-tech enterprises have more advantages in innovation performance.

\section{EMPIRICAL RESULTS AND ANALYSIS}

\subsection{Descriptive statistical analysis}

The descriptive statistical results of the main variables are shown in Table 2. For the convenience of observation, the number of patent applications, invention patent applications and non-invention patent applications are all in non-logarithmic form. According to the results in the table, the mean values of patent applications, invention patent applications and non-invention patent applications of the control group and the experimental group all increased to different extents after 2016. At the same time, by observing the mean of the number of invention patent applications and non-invention patent applications in the experimental group, we found that the number of noninvention patent applications increased by a larger range than the number of invention patent applications. However, since the innovation performance of enterprises may be affected by other factors such as the total assets of enterprises, we cannot directly see from Table 2 the promotion effect of identification policies on the innovation performance of enterprises.

TABLE II. DESCRIPTIVE STATISTICS OF MAIN VARIABLE

\begin{tabular}{|c|c|c|c|c|c|c|c|c|}
\hline \multirow{2}{*}{ Variable Name } & \multicolumn{3}{|c|}{ Experimental Group } & \multicolumn{4}{c|}{ Control Group } \\
\cline { 2 - 9 } & \multicolumn{2}{|c|}{ Before 2016 } & \multicolumn{2}{c|}{ After 2016 } & \multicolumn{2}{c|}{ Before 2016 } & \multicolumn{2}{c|}{ After 2016 } \\
\cline { 2 - 10 } & Mean & S.D & Mean & S.D & Mean & S.D & Mean & S.D \\
\hline total & 10.78 & 32.39 & 15.53 & 37.28 & 12.10 & 23.71 & 16.05 & 22.81 \\
\hline invent & 3.38 & 12.41 & 5.43 & 16.83 & 3.84 & 7.87 & 4.91 & 6.52 \\
\hline other & 5.79 & 24.66 & 6.97 & 25.71 & 8.26 & 17.84 & 11.14 & 20.03 \\
\hline size & 21.64 & 1.60 & 22.20 & 1.48 & 20.75 & 1.31 & 21.42 & 1.20 \\
\hline lev & 49.33 & 20.13 & 45.20 & 20.78 & 42.95 & 17.44 & 34.34 & 17.75 \\
\hline roa & 9.45 & 25.51 & 7.32 & 8.23 & 15.22 & 10.93 & 9.86 & 9.94 \\
\hline npm & 13.75 & 247.63 & 5.96 & 48.52 & 13.32 & 10.19 & 8.46 & 48.09 \\
\hline cr & 1.91 & 2.08 & 2.22 & 2.45 & 2.22 & 3.06 & 3.08 & 2.35 \\
\hline
\end{tabular}




\subsection{Sample matching results and PSM estimation results}

Before the propensity score matching, the balance hypothesis test should be carried out on the samples, and the test results are shown in Table 3. By observing the mean values of all variables before and after the matching, it was found that the mean differences between the experimental group and the control group decreased to different degrees, that is, there was no significant difference between the mean values of all matched variables between the experimental group and the control group. As can be seen from the standard deviation values of matching variables in Table 3, the absolute value of standard deviation of most matching variables is within $10 \%$, indicating that the data after matching is relatively balanced.

Using the "nuclear matching" method to estimate the average treatment effect of the identification policy on the innovation performance of the enterprise (see Table 4), the results show that compared with non-high-tech enterprises after matching, the identification policy can significantly improve the patent applications of high-tech enterprises, and the strategic innovation (relative effect of $66.84 \%$ ) more incentive than substantive innovation (relative effect is $47.69 \%$ ). The reasons for this result may be that, on the one hand, due to the long R\&D cycle of invention patents, large $R \& D$ investment and high failure rate, many enterprises are more inclined to engage in "short and flat fast" innovation activities in pursuing of short-term high profits, that is, to engage in research on non-invention patents. On the other hand, in order to achieve the patent target recognized by high-tech enterprises, enterprises blindly pursue the "speed" of applying for patents while ignoring the "quality" of patents. They blindly apply for national patents, resulting in a large number of "garbage patents" lacking core technology and scientific and technological innovation.

\subsection{Sample analysis}

In order to analyze the impact of identification policy on the innovation performance of different types of enterprises, this paper groups the samples according to property right attributes, the life cycle of enterprises and the total asset scale of enterprises to verify hypothesis 2 . The results are shown in Table 5.

\subsubsection{Heterogeneity of the impact of identification policy on enterprise innovation performance under different property rights attributes: According to the research of Lei Genqiang[10], Xie Haiyang[11] and others, the influence of high-tech enterprises qualification identification on the innovation performance of enterprises will show heterogeneous influence due to different property rights attributes. This paper divides enterprises into state-owned enterprises and non-state- owned enterprises according to different property rights. According to the estimation results, the relative effects of identification policy on the innovation performance of state-owned enterprises and non-state-owned enterprises are $36.63 \%$ and $166.09 \%$, indicating that identification policy has a significant promoting effect on the innovation performance of both, but the latter is more sensitive to policies.}

TABLE III. BALANCE HYPOTHESIS TEST

\begin{tabular}{|c|c|c|c|c|c|c|}
\hline \multirow{2}{*}{ Variable } & \multirow{2}{*}{ Sample } & \multicolumn{2}{|c|}{ Mean } & \multirow{2}{*}{$\%$ Bias } & \multirow{2}{*}{$\begin{array}{c}\text { \% Reduct } \\
\text { |Bias| }\end{array}$} & \multirow{2}{*}{ P Value } \\
\hline & & Experimental group & Control group & & & \\
\hline \multirow{2}{*}{ size } & before matching & 21.087 & 21.918 & -57.8 & & 0.000 \\
\hline & after matching & 21.087 & 21.221 & -9.4 & 83.8 & 0.191 \\
\hline \multirow{2}{*}{ lev } & before matching & 38.667 & 47.236 & -44.4 & & 0.000 \\
\hline & after matching & 38.667 & 39.909 & -6.4 & 85.5 & 0.381 \\
\hline \multirow{2}{*}{ roa } & before matching & 12.501 & 8.1242 & 52.6 & & 0.000 \\
\hline & after matching & 12.501 & 11.395 & 13.3 & 74.7 & 0.101 \\
\hline \multirow{2}{*}{ npm } & before matching & 12.573 & 7.594 & 40.7 & & 0.000 \\
\hline & after matching & 12.573 & 11.638 & 7.6 & 81.2 & 0.306 \\
\hline \multirow{2}{*}{ old } & before matching & 16.696 & 20.057 & -58.3 & & 0.000 \\
\hline & after matching & 16.696 & 17.228 & -9.2 & 84.2 & 0.210 \\
\hline \multirow{2}{*}{$\mathrm{cr}$} & before matching & 2.5511 & 2.0053 & 28.6 & & 0.000 \\
\hline & after matching & 2.5511 & 2.4459 & 5.5 & 80.7 & 0.496 \\
\hline
\end{tabular}

Since it is relatively difficult for non-state-owned enterprises to obtain financing, non-state-owned enterprises will have more funds for $R \& D$ activities after obtaining the certification. Compared with state-owned enterprises, non-state-owned enterprises, in order to win in the fierce market competition, will not abuse funds to meet the audit conditions or obtain more support. Instead, they tend to invest precious production resources in innovation activities to improve their competitiveness. However, we still note that non-state-owned enterprises are also more inclined to implement strategic innovation behaviors after obtaining high-level enterprise recognition. Compared with non-state-owned enterprises, although state-owned enterprises have more innovation resources, 
their management pursues short-term performance, pays insufficient attention to independent research and development, and relies too much on the economic growth mode of achieving short-term returns through the introduction of technology. At the same time, the internal innovation mechanism of enterprises is not perfect, which leads to the lack of passion for innovation activities and insufficient willingness to innovate. In addition, stateowned enterprises receive more financial support, which may "crowd out" the R\&D expenditures of the enterprises, thus detrimental to the development of enterprise innovation activities.

TABLE IV. THE AVERAGE TREATMENT EFFECT OF IDENTIFYING POLICIES ON ENTERPRISE INNOVATION PERFORMANCE

\begin{tabular}{|c|c|c|c|c|c|c|c|}
\hline Variable & Sample & Experimental Group & Control Group & Difference & Standard Error & T Value & Relative Effect \\
\hline \multirow[t]{2}{*}{ total } & unmatched & 1.9040 & 0.9998 & 0.9042 & 0.0810 & 11.16 & \\
\hline & ATT & 1.9040 & 1.2375 & 0.6643 & 0.0718 & $8.75 * * *$ & $53.68 \%$ \\
\hline \multirow[t]{2}{*}{ invent } & unmatched & 1.1204 & 0.6217 & 0.4988 & 0.0611 & 8.16 & \\
\hline & ATT & 1.1204 & 0.7580 & 0.3615 & 0.0506 & $6.12 * * *$ & $47.69 \%$ \\
\hline \multirow[t]{2}{*}{ other } & unmatched & 1.5117 & 0.7489 & 0.7628 & 0.0703 & 10.84 & \\
\hline & ATT & 1.5117 & 0.9061 & 0.6056 & 0.0729 & $8.31 * * *$ & $66.84 \%$ \\
\hline
\end{tabular}
on innovation policy performance. Therefore, according to the size of the enterprise's total assets, this paper

4.3.2 Heterogeneity of the impact of identification policy on enterprise innovation performance under different life cycles. Enterprises in different life cycles have significant differences in their ability to acquire and integrate external resources and their independent innovation ability. Therefore, referring to the classification criteria of He Jian-feng et al. [18], this paper divides enterprises whose age is less than the median of the entire sample are classified as young companies, and the rest are classified as mature companies. According to the estimation results, the relative effects of identification policy on the innovation performance of young and mature enterprises are $41.05 \%$ and $182.12 \%$ respectively, indicating that identification policy has a significant promotion effect on both young and mature enterprises, but has a greater incentive effect on mature enterprises.

In order to occupy a monopoly position in the fierce industry struggle, mature companies will choose to apply for patents to protect their intellectual property and prevent other companies from imitating and innovating. Therefore, compared with young enterprises, mature enterprises have stronger awareness of intellectual property protection. In addition, in the long-term business activities, mature enterprises have accumulated certain experience related to research and development, and the success rate of patent research and development is high. Moreover, mature enterprises are more able to attract research and development personnel with strong innovation ability, and are easier to obtain external financial support. Convenient financing channels, lower financing costs, mature "industry-university-research" cooperation mode and perfect enterprise R\&D system are all conducive to the improvement of enterprise innovation performance.

\subsubsection{Heterogeneity of the impact of identification} policy on enterprise innovation performance under different enterprise sizes. According to the research of Cai Shao-hong et al. [19], enterprise size is an important indicator influencing policy performance in the research divides the enterprise into hundred-billion-level enterprises (with total assets less than 1 billion yuan), onebillion-level enterprises (with total assets between 1 billion yuan and 10 billion yuan) and ten-billion-level enterprises (with total assets greater than 10 billion yuan). According to the estimated results, for hundred-billionlevel enterprises, the incentive effect of recognition policy on the number of patent applications is significant at the significance level of $10 \%$, but not significant for the number of invention patent applications or non-invention patent applications. For one-billion-level enterprises and ten-billion-level enterprises, the value of the relative effect is $69.05 \%$ and $164.69 \%$ respectively, indicating that the recognition policy has a significant impact on their innovation performance and has a stronger incentive effect on ten-billion-level enterprises.

According to the research of Cai Shao-hong et al.[19], enterprise size is an important indicator influencing policy performance in the research on innovation policy performance. Therefore, according to the size of the enterprise's total assets, this paper divides the enterprise into hundred-billion-level enterprises (with total assets less than 1 billion yuan), one-billion-level enterprises (with total assets between 1 billion yuan and 10 billion yuan) and ten-billion-level enterprises (with total assets greater than 10 billion yuan). According to the estimated results, for hundred-billion-level enterprises, the incentive effect of recognition policy on the number of patent applications is significant at the significance level of $10 \%$, but not significant for the number of invention patent applications or non-invention patent applications. For one-billion-level enterprises and ten-billion-level enterprises, the value of the relative effect is $69.05 \%$ and $164.69 \%$ respectively, indicating that the recognition policy has a significant impact on their innovation performance and has a stronger incentive effect on tenbillion-level enterprises. Due to the high risk of innovation activities, the strong assets of large enterprises can bear the sunk cost of innovation input and the risk of innovation failure. Therefore, large enterprises are more 
likely to carry out innovation activities and conducive to the improvement of innovation performance than small enterprises. At the same time, large enterprises tend to apply for patents to protect property rights after successful research and development. While protecting their research and development achievements from infringement, they can also earn patent fees. However, small enterprises are not only difficult to obtain patent fees, but also need to invest human and financial resources to maintain patents.

To sum up, the test results in Table 5 support the $\mathrm{H}_{2}$ proposed in this paper. The empirical results show that the effect of identification policy on the innovation

TABLE V. A SUB-SAMPLE RESEARCH ON THE IMPACT OF IDENTIFICATION POLICY ON ENTERPRISE INNOVATION PERFORMANCE

\begin{tabular}{|c|c|c|c|c|c|c|c|}
\hline \multirow{2}{*}{$\begin{array}{c}\text { Outcome } \\
\text { Variable }\end{array}$} & \multicolumn{2}{|c|}{ Property Property } & \multicolumn{2}{c|}{ The Life Cycle } & \multicolumn{3}{c|}{ Enterprise Size } \\
\cline { 2 - 8 } & State-owned & Non-state-owned & Immature & Mature & 100 million & Billions & Tens of billions \\
\hline \multirow{4}{*}{ total } & 1.3703 & 0.7868 & 1.3826 & 0.5894 & 1.3344 & 1.2635 & 0.9911 \\
\cline { 2 - 8 } & 0.5020 & 1.3068 & 0.5675 & 1.0734 & 0.1767 & 0.8724 & 1.6322 \\
\cline { 2 - 8 } & $6.25^{* * *}$ & $5.41^{* * *}$ & $6.76^{* * *}$ & $5.64^{* * *}$ & $1.68^{*}$ & $8.29^{* * *}$ & $4.75^{* * *}$ \\
\cline { 2 - 8 } & $36.63 \%$ & $166.09 \%$ & $41.05 \%$ & $182.12 \%$ & $13.24 \%$ & $69.05 \%$ & $164.69 \%$ \\
\hline \multirow{5}{*}{ invent } & 0.8253 & 0.5550 & 0.8497 & 0.3565 & 0.8055 & 0.7831 & 0.7205 \\
\cline { 2 - 8 } & 0.2766 & 0.6765 & 0.3261 & 0.4752 & 0.1209 & 0.4023 & 1.0702 \\
\cline { 2 - 8 } & $4.47^{* * *}$ & $3.56^{* * *}$ & $4.91^{* * *}$ & $3.76^{* * *}$ & 1.49 & $4.79^{* * *}$ & $4.09^{* * *}$ \\
\hline \multirow{5}{*}{ other } & $33.52 \%$ & $121.89 \%$ & $38.38 \%$ & $133.30 \%$ & $15.01 \%$ & $51.37 \%$ & $148.54 \%$ \\
\cline { 2 - 8 } & 0.9938 & 0.6105 & 1.0142 & 0.4224 & 0.9451 & 0.9237 & 0.7703 \\
\cline { 2 - 8 } & 0.4661 & 1.2118 & 0.5211 & 0.9657 & 0.1460 & 0.8458 & 1.4501 \\
\cline { 2 - 8 } & $6.06^{* * *}$ & $5.32^{* * *}$ & $6.46^{* * *}$ & $5.33^{* * *}$ & 1.50 & $8.39^{* * *}$ & $4.19^{* * *}$ \\
\hline
\end{tabular}

a. Note: For each outcome variable, the first line is the mean value of the control group, the second line is the difference between the experimental group and the control group, the third line is the $\mathrm{T}$ value, and the fourth line is the relative effect. number of enterprise patent applications and non-

4.3.4 Robustness test. The robustness test can be carried out around two aspects: one is to change the explained variables to test whether the empirical results are reliable; the other is to change different methods to test whether the results are biased. In order to test the robustness of the results, this paper uses the second method, using the propensity score matching method to re-evaluate the implementation effect of the identified policy. From the results (see Table 6), the recognition policy has a significant positive incentive effect on the performance of enterprises is different under different property rights attributes, different life cycles and different enterprise sizes. Non-state-owned enterprises can alleviate the financing constraint problem through identification policy. Mature enterprises can make better use of identified resources by taking advantage of their own strengths. The strong financial resources of large enterprises make it easier to invest resources in innovation activities after being recognized. So the recognition policy has a more significant effect on the improvement of innovation performance of non-state-owned enterprises, mature enterprises and large enterprises. invention patent applications, but has no significant effect on the number of invention patent applications. Compared with Table 3, the estimated coefficients obtained by PSMDID have not fundamentally changed. In addition, this paper also changed the matching methods in all PSM models from the original kernel matching method to "oneto-one" matching, "one-to-three" matching and radius matching for verification, and the estimated results are consistent (see Table 7), which verified the reliability of the empirical analysis in this paper.

TABLE VI. EMPIRICAL RESULTS OF PSM-DID

\begin{tabular}{|c|c|c|c|c|c|c|c|}
\hline \multirow{2}{*}{ Variable } & \multicolumn{5}{|c|}{ Before Certification } & \multicolumn{3}{c|}{ After Certification } & \multirow{2}{*}{ DID } \\
\cline { 2 - 7 } & Control group & Experimental group & Difference & Control group & Experimental group & Difference & \\
\hline total & 0.509 & 0.973 & 0.464 & 0.724 & 1.571 & 0.847 & 0.393 \\
\hline $\mathrm{t}$ value & & & $4.18^{* * *}$ & & & $7.67^{* * *}$ & $2.47^{* *}$ \\
\hline invent & -0.571 & -0.279 & 0.291 & -0.373 & 0.053 & 0.426 & 0.135 \\
\hline $\mathrm{t}$ value & & & $3.46^{* * *}$ & & & $5.07^{* * *}$ & 1.14 \\
\hline other & 0.006 & 0.421 & 0.416 & 0.118 & 0.903 & 0.784 & 0.369 \\
\hline $\mathrm{t}$ value & & & $4.26^{* * *}$ & & & $8.06^{* * *}$ & $2.70^{* * *}$ \\
\hline
\end{tabular}

TABLE VII. FULL SAMPLE ROBUSTNESS TEST RESULTS

\begin{tabular}{|l|c|c|c|}
\hline Variable & One-To-One Match & One-To-Three Match & Radius Match \\
\hline
\end{tabular}




\begin{tabular}{|c|c|c|c|c|c|c|}
\hline & T value & Relative effect & T value & Relative effect & T value & Relative effect \\
\hline total & $4.47^{* * *}$ & $38.01 \%$ & $5.71^{* * *}$ & $37.86 \%$ & $7.54^{* * *}$ & $44.30 \%$ \\
\hline invent & $3.12^{* * *}$ & $33.09 \%$ & $3.35^{* * *}$ & $27.27 \%$ & $5.13^{* * *}$ & $37.90 \%$ \\
\hline other & $4.80^{* * *}$ & $49.47 \%$ & $6.04^{* * *}$ & $51.19 \%$ & $7.45^{* * *}$ & $57.36 \%$ \\
\hline
\end{tabular}

\section{Conclusion AND Suggestion}

Based on "Administrative measures for the determination of high and new technology enterprises" revised in 2016 as the research background, this paper empirically tested the promotion effect of the identification policy on the innovation performance of enterprises by using the financial data, patent applications, qualification recognition and other relevant data of Shanghai and Shenzhen A-share listed companies from 2013 to 2018. The results show that the identification policy has a significant incentive effect on enterprise innovation performance, especially on strategic innovation represented by the number of non-invention patent applications. The results of sample regression show that compared with state-owned enterprises, the identification policy has a more obvious incentive effect on innovation of non-state-owned enterprises. Compared with young enterprises, the policy is more effective in stimulating mature enterprises. The bigger the enterprise is, the more sensitive it is to the identification policy.

On the grounds of the above research conclusions, the following suggestions are proposed: First, set preferential tax rates for different types of enterprises. When making policies, the government should fully consider the property rights of enterprises, the life cycle of enterprises and the total asset scale of enterprises. For example, considering that young enterprises are more difficult to obtain financing than mature enterprises, the government should give more support to young enterprises and implement lower tax rates. Second, we should guide enterprises to make substantive innovations. It can be seen from the empirical results that the identification policy has a greater impact on the number of non-invention patent applications, but non-invention patents do not improve the core competitiveness of enterprises. When reviewing the qualifications of high-tech enterprises, the government should implement different rewards and punishments based on the company's previous research and development performance, and implement measures such as financial subsidies for enterprises that perform substantive innovation. Third, we should stimulate the innovation vitality of state-owned enterprises, highlight the innovation-oriented evaluation of state-owned enterprise personnel, improve the reward and punishment system for state-owned enterprise $R \& D$ personnel and promote the equity incentive system on a trial basis to mobilize state-owned enterprises' enthusiasm for innovative activities. Fourth, improve the identification policies. In order to avoid the motivation heterogeneity of enterprises applying for the identification of high-tech enterprises, government departments should strictly review the process in the identification process, increase the evaluation of enterprises' actual $\mathrm{R} \& \mathrm{D}$ activities and the inspection of R\&D results. We should constantly strengthen the follow-up supervision of enterprises, set higher supervision standards for those enterprises that have passed the identification, and set up punishment measures such as tax recovery for enterprises that do not meet the standards.

\section{Acknowledgment}

Supported by Scientific Research Project of Beijing Educational Committee(SM201811232001) and Beijing Social Science Fund(17YJB007)

\section{RefERENCES}

1. Busom I, Corchuelo B, Martinez-Ros, E. Tax incentives or subsidies for business R\&D?[J]. Small Business Economics, 2014, 43(3):571-596.

2. Rao, Nirupama. Do tax credits stimulate $R \& D$ spending? The effect of the R\&D tax credit in its first decade[J]. Journal of Public Economics, 2016, 140(8):1-12.

3. Yu F, Guo Y, Le-Nguyen K, et al. The impact of government subsidies and enterprises' R\&D investment: A panel data study from renewable energy in China[J]. Energy Policy, 2016, 89: 106113.

4. Chen Zhen-zhen;He $\mathrm{Yu} ; \mathrm{Xu}$ Chang-sheng. R\&D Performance of High-tech Enterprise Certification: Evidence from A-share Listed Companies [J]. Forum on Science and Technology in China, 2019(7): 1-10.

5. $\mathrm{Xu}$ Ling-ling;Liu Fang. High-tech enterprise identification, financial development level and enterprise innovation [J]. Finance and Accounting Monthly, 2018(11): 37-45.

6. Sun Gang. Can Selective High-tech Industry Policies be Implemented Accurately? --Evidence based on the Identification of " High-tech Enterprises " [J]. Economist, 2018(8): 75-85.

7. Xu Chang-sheng;Kong Ling-wen. Does the Hightech Enterprise Certification Inspire Innovation?- The Regression Discontinuity Designs Based on the Data of A-share Listed Companies in China [J]. ast China Economic Management, 2017(10): 5-10.

8. Liu Li. Evaluating the innovation incentive effects of administration of high-tech enterprise indentification:evidence from Hubei province [D]. Central China Normal University, 2019.

9. Tan Long;Liu Wen-lan; Song Sai-sai. Empirical Study on Promoting Effect of New-high Tech Enterprise Certification on Patent Application Rising[J]. Technology Economics, 2013, 32(4): 1-6. 
10. Lei Gen-qiang, Guo Yue. Does the High-Tech Enterprise Identity Policy Promote Innovation? -Evidence from Listed Companies in China [J]. Public Finance Research, 2018(9): 32-47.

11. Xie Hai-Yang;Cao Shao-peng;Gao Min. Research on the Validity of High-tech Qualification Certification Policy_Based on the Test of DID-PSM Method [J]. Modern Economic Research, 2017(9): 75-82.

12. Zhou Wei. The Impact of the Recognition Policy of High-tech Enterprises on Enterprise Innovation in Hunan Province [J]. Journal of East China Institute of Technology, 2018, 37(3): 238-241.

13. $\mathrm{Xu}$ Ling-ling. Identification of High-tech Enterprises,Political Connections and Private Enterprises ' Technology Innovation [J]. Management Review, 2017, 29(9): 84-94.

14. Zeng Jing-jing;Gong Qi-hui;Wang Qing. Performance Evaluation of New High-Tech Enterprise Certification Policy in China: based on Difference-in-Difference Model Empirical Analysis [J]. Science \& Technology Progress and Policy 2019, 36(9): 118-125.
15. Zhang Yu. Government Incentives,Enterprise Life Cycle and Performance-Research on Listed Companies in High-tech Industries[D]. North University of China, 2019.

16. Ye Ming-que;Wang Kun-qing. Impact of government R\&D investment on enterprise innovation performance-An empirical study based on Shanghai high-tech enterprises [J]. Science Research Management, 2019, 40(7): 78-86.

17. Li Wen-jing and Zheng Man-ni. Is it Substantive Innovation or Strategic Innovation ? --Impact of Macroeconomic Policies on Micro-enterprises ' Innovation [J]. Economic Research Journal, 2016, 51(4): 60-73.

18. He Jian-feng;Zhang Xiao-jing. The Influence of Rising Labor Cost on Enterprise Innovation [J]. The Journal of Quantitative \& Technical Economics, 2018, 35(8): 56-73.

19. Cai Shao-hong;Peng Chang-sheng;Yu Li-ping. Do The Innovation Policy Benefit SMEs? [J]. China Soft Science, 2019(9): 37-50. 